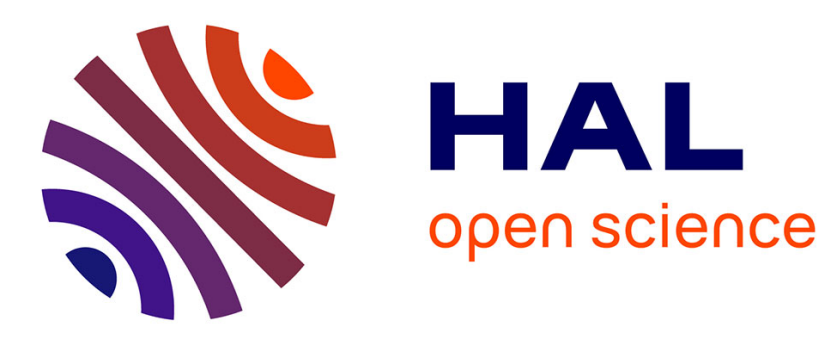

\title{
Deterrent effect of imprisonment
}

\author{
Roberto Galbiati, Francesco Drago
}

\section{To cite this version:}

Roberto Galbiati, Francesco Drago. Deterrent effect of imprisonment: Draft article for Encyclopedia of Criminology and Criminal Justice, Springer-Verlag. 2012. halshs-00834005

\section{HAL Id: halshs-00834005 https://shs.hal.science/halshs-00834005}

Preprint submitted on 13 Jun 2013

HAL is a multi-disciplinary open access archive for the deposit and dissemination of scientific research documents, whether they are published or not. The documents may come from teaching and research institutions in France or abroad, or from public or private research centers.
L'archive ouverte pluridisciplinaire HAL, est destinée au dépôt et à la diffusion de documents scientifiques de niveau recherche, publiés ou non, émanant des établissements d'enseignement et de recherche français ou étrangers, des laboratoires publics ou privés. 


\section{Deterrent effect of imprisonment}

This manuscript is a working draft of a voice in preparation for Encyclopedia of Criminology and Criminal Justice, Springer

\section{Roberto Galbiati}

OSC and Department of Economics, Sciences Po Paris

\section{Francesco Drago}

University Federico II Naples and CSE

\section{Notes \& Documents}




\section{Résumé :}

Cet article offre un résumé concis des travaux sur les effets de l'emprisonnement sur les taux de criminalité et la récidive. Nous mettons en évidence les effets liés à deux formes de dissuasion, générale et spécifique. Enfin, nous présentons les questions de recherche qui restent ouvertes.

Pour citer ce document :

Galbiati Roberto, Drago Francesco (2012). « Deterrent effects of imprisonment », Notes \& Documents, 2012-01, Paris, OSC, Sciences Po/CNRS.

Pour une version électronique de ce document de travail et des autres numéros des Notes \& Documents de l'OSC, voir le site web de l'OSC : http://osc.sciences-po.fr/publication/pub_n\&d.htm

\section{Abstract:}

This paper provides a sintetic review of the literature concernig the effects of imprisonment on crime rates and on recidivism. We hghlighht both the effects depending on general and specific deterrence as well as open research questions.

Readers wishing to cite this document are asked to use the following form of words:

Galbiati Roberto, Drago Francesco (2012). "Deterrent effects of imprisonment”, Notes \& Documents, 2012-01, Paris, OSC, Sciences Po/CNRS.

For an on-line version of this working paper and others in the series, please visit the OSC website at: http://osc.sciences-po.fr/publication/pub_n\&d.htm 


\section{Overview}

During the last decades societies has largely used incarceration as a central crime control tool. Between 1970 and 2008 the prison population per 1,000 inhabitants increased by a factor of more than 4.5 in the US. Despite a dramatic difference in levels, prison population exist between the two sides of the Atlantic also in Europe prison population increased by a factor between 2 and 3 over the period 1970-2008. This massive increase in incarceration had been coupled with a strong debate in social sciences over the magnitude of its impact on crime rates and over the reasons why crime rates might react to changes in prison population. Those favoring an increase in the severity of the criminal justice system have often argued that increasing prison sentences will lead prospective criminals to reduce their criminal activity. Criminals in fact would weight costs and benefits of crime and an increase in the cost of criminal activities following longer expected prison sentences will induce a subset of them to refrain from engaging into crime. Those holding an opposite view maintained that an increase in incarceration might have a negative net effect. One of the main arguments against an increase in the severity of incarceration system maintains that while imprisonment may temporarily constraint inmates thus preventing them from criminal activity (incapacitation), the negative impact of longer or harsher incarceration for those who are incarcerated may enhance subsequent levels of criminal activity.

Which of the two views is more plausible crucially depends on the relative weight of the two effects: the behavioral response of prospective criminals with respect to an increase in expected sentences (general deterrence) and the behavioral consequences of longer or harsher prison sentences for those that experienced incarceration (specific deterrence)

Overall, estimating the relative weight of these two effects is fundamental to the understanding of whether the actual incarceration rates are at the optimal level. It is clear that prison sentences do not deter all the individuals from committing crime (otherwise prisons would be empty), but only a subset of all potential criminals. Therefore an increase in the severity of prison sentences increases the incarceration rates. An incarceration rate is set at the optimal level if the social cost of incarcerating an additional individual (at that incarceration rate) is not below the social benefit deriving from the prevention of an eventual crime committed by that individual. While it is very difficult to compute the cost and the benefit from incarcerating an additional individual, it is very important to understand how potential criminals respond to prison sentence severity and the criminogenic effect of prisons. Both these effects enter the cost and the benefit from increasing the serverity of prison sentences and incarceration rates. 


\section{Fundamentals of Deterrence Effects of Imprisonment.}

\subsection{Definitions}

In order to better understand what is the meaning of deterrence effects of imprisonment it is useful to refer to the pioneer economic model of crime Gary Becker (1968). Becker's contribution is crucial because it provides a simple theoretical framework presenting the commission of a crime as a rational choice reflecting a cost-benefit comparison. In this simple framework an individual chooses to commit a crime if the expected payoffs (weighted by a utility function) from the commission of a crime exceeds the payoffs from not committing a crime. The expected payoff from committing a crime depends on the prison sentence from that crime. the probability to be caught and convicted to a prison sentence and the gain deriving from that crime. The expected payoff from not committing a crime depends on the payoff from legal activities (e.g. expected wage from a legal job, disutility from working). An individual compares the expected costs and benefits from committing a crime and behaves accordingly. If the potential criminal opts for the criminal activity we infer that he faces a net expected gain from the activity despite the expected punishment. This simple reasoning highlights that the probability of being punished and the costs associated with being punished are crucial elements for a criminal's choice. Rephrasing this point: the theory predicts that changes in the certainty and the severity of the punishment will induce changes in criminals' behavior.

The probability of punishment will depend upon many factors (number of police forces, efficiency of the justice system, apprehension technology among others). For what concerns the severity of the punishment two elements are crucial. One is length of the expected sanction and in particular the expected length of imprisonment. The other fundamental aspect is given by the conditions of detention. Both longer and harsher expected prison sentences represent a higher cost for prospective criminals. According to this framework, by varying these three elements a policy maker can affect criminals' choice and thus can affect the level of crime rates.

The general deterrent effect of imprisonment is the response of potential criminals to the expected cost associated with the decision to commit a crime. This is an ex-ante perspective. The choice of committing a crime is affected by the expected level of punishment that in turns reflects the probability of apprehension and conviction, the expected length of imprisonment and the expected harshness of the imprisonment.

Since a share of those that are apprehended and convicted will actually spend some time in prison it is natural asking if the time spent in prison and the condition of detention will affect criminals' propensity to commit a crime once they are released. If we assume that incarceration leads criminals to update their beliefs about the consequences of punishment, we might expect that having experienced harsher punishment should reduce the inmates' propensity to recommit a crime once released. Under this perspective imprisonment is an experience good. Criminals ex ante do not perfectly know the cost of spending time in. Once they are convicted to a prison sentence and they make the experience of incarceratation, ex-post they update their knowledge of prison conditions. Experiencing imprisonment and staying in prison longer will affect criminals knowledge of the prison environment and on turn their 
evaluation of expected costs of committing a crime once they are released. For this reason those having experienced harsher prison conditions should be less prone to recommit a criminal act. This is known as the specific deterrence hypothesis. On the other hand, however, experiencing harsher prison conditions could also imply higher propensity of committing crime once released. In fact, harsher prison conditions may lead to a higher human capital deployment and worse labour outcomes for former inmates (Waldfogel, 1994). Since these factors affect the relative benefits of engaging into legal or criminal activities they will affect former inmates' criminal choice. In this case the theoretical predictions are not clear-cut. Hence, understanding the specific deterrence effects of imprisonment is ultimately an empirical question.

\subsection{Current Issues and Controversies}

Understanding how and whether potential criminals respond to changes in expected prison sentences (general deterrence) and if prison experience affects former inmates' decisions to recommit a criminal act after release (specific deterrence) has been the object of a large and growing empirical literature. Most of the studies have focused on the American criminal justice system but in recent years several studies have provided evidence on European ones. Many of these studies apply modern econometric techniques allowing to get rid of potential confounding factors that could affect the interpretation of the findings. These exercise thus provide important insights that could usefully inspire crime control policy interventions. Despite these relevant advances, international comparisons are still very difficult given the large diversity of the specific national contests.

Empirical studies aiming at understanding to what extent potential criminals respond to manipulations in expected prison sentences and/or to what extent the prison conditions experienced during incarceration by former inmates affect their post release behavior, need to face some major empirical challenge.

For what concerns general deterrence, longer prison sentences might deter potential criminals but might also reflect changes in the general attitude toward criminality or might anticipate expected increases in crime rates. For this reason it is hard to disentangle if there is any causal effect of increasing expected prison sentences on criminal behavior. The same reasoning applies to the general deterrent effects of expected harshness of prison conditions. For example overcrowded prisons might affect potential criminals' choices because more crowded prisons imply higher expected costs of detention but at the same time will mechanically reflect an increase in crime rates. Pinning down any general deterrence effect of harsher prison conditions is thus particularly challenging.

Understanding the specific deterrent effect of prison suffers from the same empirical challenges. Inmates suffering harsher prison conditions will probably react to them once they will be released but being assigned to harsher prisons might reflect higher individuals' dangerousness. Thus, even in the presence of detailed individual level data it is hard to understand if and to what extent prison conditions have any causal effect on former inmates behavior without some clear empirical research design able to break the simultaneity between prison conditions and individuals' propensity to re-offend. 
For these reasons most of the recent research have focused on specific case studies allowing to quasi-experimentally disentangle the effect of the crucial policy manipulable elements on individuals' choices.

In particular researchers have investigated the general and specific deterrent effects of prison sentences' length and of prison conditions. Related to this last point some interesting studies have focused on an important but largely neglected aspect of incarceration: the effect of peers' characteristics and behavior on inmates' post release behavior. This aspect is crucial since there is a large and consistent evidence that peers' might affect people behavior in many domains, ranging from educational attainment to job search. If the same holds for crime, prisons might be a sort of criminal school were inmates learn or are influenced from each other. Thus other inmates' characteristics or behavior might crucially affect ones' post release behavior.

\subsection{General Deterrence}

\subsubsection{Prison sentences length and prison conditions}

Evidence on the effects of the severity of punishment on criminal activity is growing and consistently point out that, as predicted in the standard economic/rational choice approach to crime, potential criminals take into expected sentences' length when they decide whether to commit a criminal act. To understand this effect, most works in this field have studied the effect of incarceration rates on aggregate crime rates. In order to break the simultaneity between prison population and crime rates researchers have resorted to case studies exploiting exogenous variation in prison population or expected prison sentences' length. An influential study based on US State level data, Levitt (1996), shows that releasing one prisoner is associated with an increase of 15 crimes per year. This estimate, however, includes deterrence and incapacitative effects. A major change in expected prison sentences in US have been introduced in some States through sentence enhancements' laws such as California's 'three strikes and your out' law or Proposition 8. These laws provide researchers with some variation on expected prison sentences' length useful to disentangle deterrence and incapactiation. Among these studies Kessler and Levitt (1999) exploiting sentence enhancements targeting the most frequent and dangerous criminals find that some crime rates fell by 4 percent after sentence enhancement, which, for example, increased the sentence for any "serious" felony offender by five years. Exploiting the increase in expected sentences induced by the California 'three strikes law' Helland and Tabarrok (2007) compare the future offending of individuals convicted of two previous strikeable offenses with that of individuals who had been convicted of only one strikeable offense but who, in addition, had been tried for a second strikeable offense but were ultimately convicted of a nonstrikeable offense. The study finds that arrest rates were about 20 percent lower for the group with convictions for two strikeable offenses providing evidence in line with previous studies.

Since the cost of imprisonment does not depend only on the expected prison sentence length but also on expected prison conditions, an important issue is to understand if and how potential criminals respond to expected harsher prison conditions. This is an interesting aspect since, setting aside ethical considerations, prison conditions are more easily manipulable than sentences' length. Such a deterrent effect of harsher prison conditions seem to exist in the US where recent research (Katz, Levitt, and 
Shustorovich 2003), using death rates among prisoners as a proxy for prison conditions, show that more punitive facilities have a small but statistically significant general deterrent effect.

These and several other studies taking seriously the econometric challenges behind the identification of the deterrent effect of prison sentences' length show that, at least for US, potential criminals take into account expected sentence length and prison severity when they have to decide whether to engage into a criminal act.

Evidence outside the US is less systematic but a recent large criminal justice policy intervention in Italy have provided researchers the opportunity to study for a large sample of former inmates what is their response to a manipulation of expected prison sentences.

The Collective Clemency Bill passed by the Italian Parliament in July 2006 provided an ideal case study to understand how people respond to exogenous variations in prison sentences. This law provided for an immediate three-year reduction in detention for all inmates who had committed a crime before May 2 nd 2006. Upon the approval of the bill, almost 22,000 inmates - about 40 percent of the prison population of Italy - were released from Italian prisons on August 1st 2006. The bill states that if a former inmate recommits a crime within five years following his release from prison, he will be required to serve the remaining sentence suspended by the pardon (varying between 1 and 36 months) in addition to the sentence given for the new crime. This is equivalent to a policy manipulating incentives to commit a crime since it commutes one month of time of the original sentence to be served in one month more of expected sentence for future crimes. More importantly, this institutional framework manipulates prison sentences at the individual level in a random fashion. In particular, conditional on inmates' original sentences, the variation in the remaining sentence at the date of the pardon (and hence in the expected sentence for any crime) depends only on the date of an inmate's entry into prison, which is plausibly non correlated with individuals' characteristics potentially affecting their propensity to recidivate. The variation in the remaining sentence at the date of the pardon can thus be used to identify the causal impact of an a manipulation of expected prison sentences on individuals' propensity to recommit a crime. Research based on data from the Italian experiment (Drago, Galbiati and Vertova 2009) show that a marginal increase in the remaining sentence reduces the probability of recidivism by 0.16 percentage points ( 1.3 percent). This means that for former inmates, one month less time served in prison commuted into one month more in expected sentence significantly reduces their propensity to recommit a crime. Interestingly, this deterrent effect of prison sentences is quite homogeneous across inmates with different individual characteristics but individuals convicted to relatively longer sentences do not seem to be deterred. This suggests that longer sentences ex ante deter more but experiencing longer time in prison might be deleterious in terms of former inmates' behavioral response to incentives.

Given this apparently consistent evidence suggesting that longer and harsher prison sentences deter crime it could be tempting to draw immediate policy conclusions. However, it is extremely important to be cautious in making this further step. In fact it is still far to be clear for researchers what are the most cost effective means to reduce criminal activity and even just looking at deterrence it is far from clear if criminals respond more to an increase in the severity rather than an increase in the certainty of punishment (Durlauf 
and Nagin 2011). For example, in a pionnering study, DiTella and Shargrodsky (2009) show that electronic monitoring is more effective than incarceration in reducing ex-post former prison inmates' criminal behavior. Moreover existing evidence suggests that the effect of the aggregate impact of changing prison conditions on crime rates is relatively small (Katz et al. 2003). Finally, the evidence from the Italian case suggesting that those having spent long prison sentences do not respond to a manipulation in prison sentence after release suggests that the ex-post effects of prison sentences might compromise the ex-ante deterrent effect.

Since most criminals experiencing prison sentences experience multiple prison conditions during their life and constitute the core of the criminals population, for the reasons explained above, understanding specific deterrence and the effect of incarceration on those that have experienced it is a crucial challenge for social scientists.

\subsection{Specific Deterrence}

\subsubsection{Prison conditions and time served}

Opening the prison black box we find very different punitive situations in terms of overcrowding, health services, social activities for inmates and so on. All these elements might impact former inmates' propensity to reoffend. Those inmates having experienced harsher prison conditions might be more deterred by the threat of future sentences but these same people might suffer from more human capital deployment and worse health conditions thus facing lower opportunity costs of criminal activity. of engaging. While the issue of the deterrent effects of prison treatment appears particularly important for both researchers and policy makers, the empirical evidence is scarce. Only a few recent works analyze the effects of prison conditions on criminal behaviour. The lack of evidence is mainly due both to the difficulty in obtaining access to reliable data on prison conditions and to the identification challenges faced by researchers interested in understanding how criminals respond to prison conditions. Nonetheless, the few existing studies focusing on the issue of prison conditions and former inmates behavior provide some crucial knowledge on the phenomenon. Focusing on women incarceration conditions recent evidence exploiting the expansion of female penal system capacity in the United States (Bedard and Helland 2004) show that, on average, increasing the distance of detention facilities from inmates' home tends to lower the female crime rate. Despite this results seem to conform to the deterrence hypothesis, from this case study it is hard to understand if the deterrent effect is driven by the response of formers inmates or by the reaction of criminals who had never received a prison treatment (or both). Exploiting quasi-experimental designs and individual level data is crucial to separate general deterrence from specific deterrent effects of incarceration conditions. Studies using these two ingredients cast doubts on the capacity of harsher prison conditions to reduce former inmates' propensity to recidivate. By exploiting a discontinuity in the assignment of federal prisoners to security levels, American economists provide evidence that serving a sentence in a higher security prison implies a higher post- release propensity to commit a crime (Chen and Shapiro 2007). In a similar vein, exploiting some randomness in the facility assignment rules and individual level data on inmates post release behavior an Italian case study (Drago, Galbiati and Vertova 2011) show that being assigned to a prison where mortality is higher increases the propensity to recidivate for former inmates. 
For the analysis of the effect of the amount of time spent in prison, recent quasi experimental evidence from US and France (Kuziemko 2007; Maurin and Ouss 2009) suggest that spending more time in prison all else equal should reduce the propensity to recidivate for former inmates.Taken together the results of recent empirical literature focusing on the specific deterrent effects of prison in terms of prison sentences' length and detention conditions quality are mixed. Thus, deriving any strong policy conclusion based on the current evidence is not only hard but also non recommended.

\subsubsection{Peer effects between prison inmates}

Experiencing incarceration might effect post release inmates' behavior not only through the effects of time spent in, physical prison conditions or in-prison activities but also through the effect of interactions with other inmates. Social scientists have documented that the exposure to peers' actions and characteristics might have a strong impact on individuals' behavior in various domains ranging from school performance to labor supply decisions. Peers might influence one's decision by providing information, by affecting social norms, constraints to action and various other channels. Individual choices to engage into criminal behavior are also plausibly affected by peers' influence since peers affect the criminal markets' conditions, provide information about criminal opportunities and act together. Estimating the impact of peer effects on criminal behavior and understanding the mechanisms through which peers affect individual criminal participation are of primary importance in the design of effective policies to prevent crime (Manski 1993; Glaeser et al. 1996). Understanding if peer effects between prison inmates exist and estimating their magnitude is crucial to understand how prison experience affects former inmates' behavior. In this sense potential peer effects are a crucial component of prison experience and understanding them is particularly important to assess overall general and specific deterrent effects of prison and thus to understand how the prison system works overall.

Peers effects between former prison inmates might take place because once in prison criminals respond to the characteristics of those they spend time with. For example, juvenile offenders serving time in the same correctional facility Florida seem to have some influence on each other's subsequent criminal behavior (Bayer, Pïntoff and Pozen 2009). The data on juvenile inmates spending some time in one of 169 Florida correctional facilities provide a complete record of past crimes, facility assignments, and arrests and adjudications in the year following release for each individual. These kind of data have allowed researcher to solve the simultaneity problem that usually hamper the identification of peer effects. From the Florida's case study we learned that peers exert their influence by influencing affects individuals who already have some experience in a particular crime category (Bayer, Pïntoff and Pozen 2009). This evidence support the idea that prisons are a sort of criminals' school.

Another plausible mechanism underlying peer effects is the maintenance of prison peer groups after release and the presence of complementarities in post-release behavior (e.g. joint crime production). Sociological and qualitative research on prison gangs (Skarbek 2010; Leeson and Skarbeck 2010; Fleisher and Decker 2001) and on former Italian inmates' post-release networks (Baccaro and Mosconi 2004; Santoro and Tucci 2006) supports this interpretation. Moreover, exploiting data on the Italian prison experiment described above researchers have shown that former inmates from the same nationality that spent time together in the same prison facility tend to influence each others' post release behavior (Drago and Galbiati 2012). In particular, criminals respond to the behavior of those they spent time in prison with by 
OSC - Notes \& Documents N²012-01

Galbiati Roberto, Drago Francesco - Deterrent effects of imprisonment

increasing their propensity to commit crime if others' criminal activity increases. This suggests that that peer groups formed in prison remain the same after release and thus peers' will continue to influence each other even after release from prison.

Thus, peer effects are a crucial aspect of inmates' interaction that have to be carefully taken into account in order to understand the overall effect exerted by prison sentencing on individuals' criminal choices.

\subsection{Directions for future research}

Despite a growing research effort clean evidence about general and specific deterrent effects of prison is still scarce. Some more systematic research and a larger number of specific country case studies is most welcome to fill the knowledge gap.

Given that identifying causal relation is particularly difficult in this domain a more systematic access and use of individual level data is needed. Some particularly fruitful lines of research should focus on understanding the relative weight of severity and certainty of punishment in determining the overall general deterrent effect of prison sentences. Continuing in the effort to open the specific deterrence black box is crucial in order to understand the dynamics of future crime rates since a large share of those that have been incarcerated in US and Europe during the last decades will be released in the following years.

Finally these research building blocks could and hopefully will be used to build a more comprehensive approach to determine the immediate and dynamic future effects of manipulating the length and harshness of prison sentences.

\section{REFERENCES}

Baccaro, Laura and Giuseppe Mosconi. 2004. "Il girone dei dannati: ovvero il fenomeno della recidiva". Rassegna Penitenziaria e Criminologica 2: 212-37.

Bayer, Patrick, Randi Hjalmarsson and David Pozen. 2009. "Building Criminal Capital behind Bars: Peer Effects in Juvenile Corrections". Quarterly Journal of Economics 124 (1): 105-147.

Bedard, Kelly,and Eric Helland. 2004. "The Location of Women's Prisons and the Deterrence Effect of Harder Time". International Review of Law and Economics 24: 147-167.

Becker, Gary S. 1968. "'Crime and Punishment: An Economic Approach". Journal of Political Economy 76: 169-217.

Chen, M. Keith and Jesse M. Shapiro. 2007. "Do Harsher Prison Conditions Reduce Recidivism? A Discontinuity-Based Approach". American Law and Economics Review 9(1): 1-29.

Di Tella, Rafael and Ernesto Schargrodsky. 2009. "Criminal Recidivism after Prison and Electronic Monitoring". National Bureau of Economic Research Working Paper 15602.

Drago, Francesco, Roberto Galbiati and Pietro Vertova. 2009. "The Deterrent Effects of Prison: Evidence from a Natural Experiment". Journal of Political Economy 117(2): 257-80. 
OSC - Notes \& Documents N ${ }^{\circ} 2012-01$

Galbiati Roberto, Drago Francesco - Deterrent effects of imprisonment

Drago, Francesco, Roberto Galbiati, and Pietro Vertova. 2011. "Prison Conditions and Recidivism." American Law and Economics Review 13 (1): 103-30.

Drago, Francesco and Roberto Galbiati. 2012. "Indirect Effects of a Policy Altering Criminal Behavior: Evidence from the Italian Prison Experiment". American Economic Journal: Applied Economics, 2.

Fleisher, Mark S. and Scott H. Decker. 2001. "An Overview of the Challenge of Prison Gangs". Corrections Management Quarterly 5(1): 1-9.

Glaeser, Edward L., Bruce Sacerdote and Jose A. Scheinkman. 1996. "Crime and Social Interactions". Quarterly Journal of Economics 111(2): 507-48.

Helland, Eric and Alexander Tabarrok. 2007. "Does Three Strikes Deter? A Nonparametric Estimation". Journal of Human Resources 22: 309-30.

Leeson, Peter T. and David B. Skarbek. 2010. "Criminal Constitutions". Global Crime 11(3): 279-97.

Levitt, Steven D. 1996. "The Effect of Prison Population Size on Crime Rates: Evidence from Prison Overcrowding Litigation". Quarterly Journal of Economics 111(2): 319-51.

Manski, Charles F. 1993. "Identification of Endogenous Social Effects: The Reflection Problem". Review of Economic Studies 60(3): 531-42.

Maurin, Eric and Aurelie Ouss. 2009. "Sentence Reductions and Recidivism: Lessons from the Bastille Day Quasi Experiment”. IZA Discussion Paper n 3990 (February), Inst. Study Labor, Bonn.

Katz, Lawrence, Steven D. Levitt and Ellen Shustorovich. 2003. "Prison Conditions, Capital Punishment, and Deterrence". American Law and Economics Review 5: 318-43.

Kuziemko, Ilyana. 2007. "Going Off Parole: How the Elimination of Discretionary Prison Release Affects the Social Cost of Crime". Working Paper n 13380 (September), NBER, Cambridge, MA.

Santoro, Emilio and Raffaella Tucci. 2006. "L'incidenza dell'affidamento sulla recidiva: prime indicazioni e problemi per una ricerca sistematica". Rassegna Penitenziaria e Criminologica 10(1): 79-158.

Skarbek, David. 2010. "Putting the 'Con' into Constitutions: The Economics of Prison Gangs". Journal of Law, Economics, and Organization 26(2): 183-211.

Waldfogel, Joel. 1994. "The Effect of Criminal Conviction on Income and the Trust Reposed on Workmen". Journal of Human Resources 29: 62-81. 